\title{
Comparative Analysis of Variations in Human Sex Ratios of Live Births Among African Populations and at Global Levels
}

\author{
Hadgu Bariagabera, Mpho Keetile
}

\begin{abstract}
Definition: The final net live birth delivery from the mother's womb, with distinct male and female genetic traits, forms a ratio of male live births per 100 female live births, termed as Sex Ratio at Birth (SRB). Study areas and source of data: The study areas are Africa and major worldwide continents and countries. The basic data are compiled from the National Population and Housing Censuses, Demographic Sample Surveys, Demographic and Health Surveys, and Vital Registration Systems. Analytical approaches: The factors influencing the variations in SRB are identified by reviewing various documents, analysis of variance (ANOVA) techniques, and statistical measures of central tendency and dispersion. Results: The ratios are consistently higher for advanced countries than the developing countries, with highest for China and India. The ANOVA results show slight differences among the 50 African countries but show differences among the African regional states, whereas the standard deviation of the SRB among the advanced countries, including some Asian and Latin American countries shows non-significant variations. In conclusion, the mean SRB for African populations is 103 as against 106 for other countries.
\end{abstract}

\section{Keywords}

Live birth, sex ratio, factors, variations, ANOVA, standard deviation

In bio-demographic study, we learn that some embryonic fetuses could face spontaneous or induced abortions during antenatal and prenatal pregnancy stages of fertilization and conception or other situational problems in their mothers' wombs, whereas others proceed to live birth. This net outcome is delivered with distinct male and female genetic traits, termed as "sex entity". The live outcomes from the mothers' wombs, occurring during a defined time frame, are compiled and establish the ratio of male live births per 100 female live births to form Sex Ratio at Birth (SRB).

\section{RATIONALE OF THE STUDY}

The level of human sex ratio at birth renders fundamental and useful inputs to health service planning and other social and economic development planning processes. Besides, the levels of sex ratios of live births are necessary inputs to model life tables for undertaking population estimates/projections for

aUniversity of Botswana, Botswana

Correspondent Author:

Hadgu Bariagaber, Department of Population Studies, University of Botswana, P/Bag UB 00705, Gaborone, Botswana 
various development planning, monitoring, and evaluation.

In the past, African demographers generally used to take any arbitrary sex ratio, ranging between 102-106 males per 100 females. Since this study covers almost representative worldwide continents and countries, it is believed that demographers and other professionals, planners, and policy makers could have wider perspectives and choices from this paper in picking any sex ratio of interest for their general or specific planning purposes.

\section{OBJECTIVES}

The underlying major objectives of this paper are two folds: First, to review and understand the factors which contribute to the historical changes of the human sex ratios at live birth; second, it is to acquire knowledge about the extent of the convergence and divergence of the ratios and factors which brought about variations among the countries and continents at global perspectives.

\section{ANALYTICAL TECHNIQUES}

The analytical methods of the study include descriptive frequency distribution at regional, continental, and global levels. In addition, the measures of central tendency/dispersion and analysis of variance (ANOVA) are applied to test the degree of variability of sex ratios at African regional and country levels and at international levels.

\section{SOURCE OF DATA}

Ideally, the sources of data of the study should have been the outputs of continuous vital registration system of births, deaths, marriages, and other studies, such as the results of African Demographic and Health Surveys (DHS) and World Fertility Surveys (WFS), which were sourced by Michael Garenne (2002) in analysing the levels and patterns of the sex ratio of African countries. Similarly, the data sources of the authors' study are based on the secondary data which were compiled by the main international bodies from the results of various DHS, WFS, civil registration system for some European countries and the results of National Population and Housing Censuses of various countries in the world (refer to Appendixs A and B).

\section{ACCURACY OF DATA}

Concerning the quality of the live birth data, formal coverage evaluation of the male and female live birth information is not part of the mandates of this paper, but reference could be made to the UN, Manual $\mathrm{X}^{1}$ for rigorous indirect evaluation of the accuracy of the retrospective and current births and deaths data of developing countries. Furthermore, analysis of twin sex ratios at birth is not considered in this study, though there could theoretically have different features from the normal single birth delivery in certain societies. For example, in a certain study in Nigeria and Ghana (West Africa), twin birth delivery was believed to have distorted the patterns of the sex ratios at live birth (Pongou 2013). Although the findings of that author could be noted as interesting, the incidence of twin births is too low to affect the overall sex ratios of the live births at country, regional, and worldwide levels.

In this study, therefore, we briefly touch on some possible inherent empirical errors that commonly occur during data collection of live births and deaths during population censuses and demographic surveys. For example, empirical evidence shows that incomplete or inaccurate reports or even omissions of the live births, or due to short and long reference period errors of reporting vital events, have been apparently common in Africa and other developing world.

A good example is the Russian case where premature live born babies, with less than 28 weeks of 
gestational period, or less than 1,000 grams in weight, or less than 35 centimeters in length, were observed not to have been counted as a live birth until they had survived seven days after delivery (Zhang 2004). In the same country, if the live-born infant dies soon after delivery, it is not considered live birth or as a normal infant death, which led to serious underreporting by 22-25 percent below the standards recommended by the World Health Organization.

Furthermore, the high male to female live birth ratios of mainland China, which appeared to have occurred after the introduction of the "one-child policy", was suspected to have been due to underreporting of the female births or some deficiencies in the vital statistics registration system (Merli and Raftery 2000). It was further verified that the number of births reported to family planning and other administrative agencies in China was found to be significantly lower than the number obtained from the demographic surveys and population censuses.

Another interesting phenomenon is the scientific discovery of ultrasounds which facilitated the sex-selectivity of abortion of female fetuses or in some cases, the infanticide of females which resulted in high sex ratios performance in favour of male births (Catalano 2003), skewing significantly the natural occurrence of the ratios in some populations, such as China, reporting a sex ratio at birth of 1.13 and India at 1.09 (Government of India 2011).

In a nutshell, the factors which could have contributed to the male/female live birth imbalances among countries could generally be due to the empirical evidences of rapid decline in fertility; lack of women's empowerment; cultural preferences for male heirs; access to technology to selectively abort female fetuses; sex-selectivity of abortion and infanticide; large-scale in/out migration of males; and warfare, like the first world war and second world war (Hudson and den Boer 2004).

\section{REVIEW OF THE LEVELS AND FACTORS CAUSING VARIATIONS IN SEX RATIOS OF LIVE BIRTHS}

The factors which could influence the levels, sizes, patterns, and trends of the human sex ratios can be classified as exogenous and endogenous variables. These include worldwide data of demographic and socio-economic factors; gestational and environmental factors and natural factors. Their contributions to the disparities are highlighted in the subsequent subsections.

\section{Demographic Factors}

After the end of 1946 World War II, worldwide variations in the general level of sex ratios were observed. The sex ratios at birth were declined in certain European countries as opposed to high sex ratios in Qatar, Saudi Arabia, and other Gulf States as the results of probably large number of male influx in the recent years; Georgia and China reported to have a live birth ratio of 1.13 as opposed to 1.01 for the entire world populations (USA/CIA 2006, in World Factbook).

Similarly, in India, China, Congo, Kenya, Pakistan, Iraq, Bahrain, and Thailand, a large number of girls were reported to have died annually within their first five years of life due to discrimination and gendercide. The effects of violence against women, therefore, were developed into creating the male/female imbalances in many countries where more girls were estimated to have been killed in the last 50-60 years as compared with males who were killed in all the wars of the 20th century in the developing world, particularly, in China, India, and Pakistan (Kristof and WuDunn 2009). Performing high sex ratios in those countries has been influenced by cultural preferences for one sex, typically males over females. For example, in India, Northern Ethiopia, and Highland Eritrea, a son was used to be preferred as an "asset", since he could earn and support the family; 
whereas a daughter used to be looked as a "liability" since she would be married off to another family and so would not contribute financially or otherwise to her parents.

This idea is inconsonant with the patriarchal society where the single most important factor which skews the sex ratio in favour of males, is built in some cultures, which have been motivated by the burden of raising a dowry for daughters' marriages. These cultural preferences and social practices in certain societies tend to favour males as opposed to females, with significant variations for younger mothers, 15-24 years old and older mothers, 40-49 years old (Jacobsen, Møller, and Mouritsen 1999).

On the other hand, studies on 1.7 million births in 33 states of USA and a large number of births in Denmark found out that maternal age did not have statistically significant effect on the variations, though more male babies were born to younger fathers than to older fathers and also suggested that social factors in certain societies, such as early marriage and fertile couples, may play a role in raising sex ratios at birth (Ruder 1985).

Applying contingency tables of chi-square tests and regression analysis, Jacobsen et al. (1999) studied the pattern of the sex ratio for about 816,000 children born in Denmark and found out that sex ratio got decreased with increased number of twin births and with paternal age, whereas no significant and independent effect was observed for maternal age, birth order, or other natural factors. In contrast, increasing paternal and maternal ages, plural birth, birth order, gestational weeks, race/ethnicity, parent's health history, parent's psychological stress, and environmental conditions are among the influencing factors which appeared to manifest declining trends in the ratios in favour of females (Bernstein 1958).

Controlling for birth order as well as parents' age and race/ethnicity, different trends in the ratio were apparent. The white racial group of USA, for instance, continued to show a statistically significant decline, while in other racial groups, the ratio manifested small declines among the Japanese, Native Americans, and little or no change among Black American society, but an increase in the Chinese racial group. It was then concluded that the decline in male births in USA may largely be attributable to changes in demographics (David, Gottlieb, and Stampnitzky 1998).

\section{Socio-economic Factors}

In general, sex ratio imbalances have many social and economic consequences. Social unrest and unstable family formation disturbs the holy relationship among communities of a given society. A large male outmigration due to economic difficulties may disturb the male/female balance where sex ratio tends to be low at place of origin, disenabling females in getting partnership, whereas high ratios make it easier for women to marry, but harder for men, possibly disturbing the balance in the sex ratio at birth (Florida 2008; Bethmann and Kvasnicka 2013; Heer and Grossbard-Shechtman 1981).

It was reported that, as late as 2011, the social and racial variations in sex ratios in the economically emerging countries, like China and India, manifest significantly higher above the mean ratio recorded in the United States, which is 1.06 against 1.13 for China and 1.12 for India. Similar to the Asian countries, a number of European, Middle East, and Latin American countries have recently reported high sex ratios at birth, ranging between 1.06 and 1.14 (U.S. Department of Health and Human Services 2011; James 2011). However, some scientists admit that they do not have definitive proof that sex-selectivity of abortion is actually happening or that there are no natural reasons for the persistently high sex ratios at birth (Anderson and Bergstrom 1998). Another hypothesis has been inspired by the recent and persistent high sex ratios at birth observed in Georgia and Armenia (Orthodox Christian societies) and Azerbaijan (a Muslim society) after their dissociation 
from the Soviet Union and they recorded sharp increase in their sex ratios ranging between 1.11 and 1.20 (Anderson and Silver 1986). Similarly, Mesle, Vallin, and Badurashvili (2007) considered the hypothesis that the high sex ratio at birth may be the social trend of more than two children per family and birth order, possibly affecting the sex ratio in this region of the world. They also considered the hypothesis that sons are preferred in these countries of the Caucasus where the ultrasound-scans and a practice of sex-selective abortion might have caused to the high sex ratio phenomenal prevalence.

A study by Catalano on women of East Germany, who did not opt to abortions, indicated that the best hypothetical reason for the disparities in the ratios was believed to have been due to collapsing economies which lower the human sex ratio, while booming economies raise the sex ratio at birth. Furthermore, Catalano noted that these trends might have been related to the observed trends of the incidences of very low birth weight from maternal stress, during certain macroeconomic circumstances (Oster et al. 2008).

\section{Natural Factors}

In most populations, adult males tend to have higher death rates than adult females of the same age due to natural causes, such as cardio-vascular and related diseases, accounting for by far the majority of deaths. Similarly, a study in the USA (2006) indicated that an adult middle-aged male was three to six times more likely to become a victim of a homicide and about three to four times more likely to die in an accident than a female of the same age (Catalano, Bruckner, and Smith 2008; Ein-Mor et al. 2010). This incidence could be considered an incremental quantity to higher life expectancy of females, consistent with the Regional Model Life Tables ${ }^{2}$.

On the other hand, the sex ratios at birth during 1970-2002 in the US ranged between 1.03-1.05 for all racial groups and 1.07 for mothers of Chinese or
Filipino origin. Among Western European countries (2001), the ratios ranged from 1.04 for Belgium to 1.07 for Switzerland, Italy, Ireland, and Portugal. In the aggregated results of 50 DHS data of African countries, the ratio is 1.03 , though there is also considerable country-to-country variations (refer to Appendixs A2 and A3).

Similarly, an extensive study of sex ratios at birth in the United States (2005) showed interesting evidences that the total sex ratio at birth for mothers having their first babies was 1.06 , but the ratio consistently decreased with each additional baby, declining from 106 to 103 . When examination was made with respect to mothers' ages, the overall ratio was reported to be 1.05 for mothers aged 25 to 35 at the time of birth; while mothers who were below the age of 25 or above 40 had babies with a sex ratio ranging between .94 to 1.11 , with a mean value of 1.04 (James 1987; 2008; Mathews and Hamilton 2005).

Furthermore, racial differentiations in the ratios were noticeable where American mothers of Hawaiian, Filipino, Chinese, Cuban, and Japanese mothers reported the highest sex ratio, as high as 1.14 with an average of 1.07 over the 62-year study period. This study also found that the sex ratios at birth (1981-2006) were lower in both Black and Hispanic ethnic groups when compared with white counterparts (Florida 2008; Kristof and WuDunn 2009).

\section{Gestational and Environmental Factors}

A research paper published by Branum, Parker, and Schoendorf (2009) reported that the sex ratio derived from a 25-year period (1981-2006) birth records data of the US found out that the sex ratio at birth for the white ethnic group was 1.04 when the gestational age was 33-36 weeks, but increased to 1.15 for gestational ages of less than 28 weeks, $28-32$ weeks, and 37 or more weeks. This study also found that the sex ratios at birth in the United States (1981-2006) were lower for both Black and Hispanic ethnic groups when 
compared with the white counterparts (Catalano et al. 2008). In this connection, a sex ratio at birth of 1.04 for the US white ethnic group was reported within the gestational period of 33-36 weeks, but reported 1.15 for gestational periods of less than 28 weeks and 37 or more weeks as opposed to lower sex ratios at birth among the Black and Hispanic ethnic groups between 1981-2006 (The Guardian 2007).

According to Catalano's report, cold weather is an environmental depressor and women subjected to such weather abort male fetuses in greater proportion thereby lowering the sex ratios at birth in favour of female births. On the other hand, Catalano's team found that a $1{ }^{\circ} \mathrm{C}$ increase in annual temperature predicts one more male than expected for every 1,000 females born in a year. Similarly, Anderson and his partner have studied 138 years' (1865 to 2003) data of human sex ratio at birth and found an increased excess of male births during a period of the exogenous stress and during warmer years where the warmest period over the 138 years showed sex ratio at birth peaked at about 1.08 in Northern Europe.

Furthermore, causes of stress during gestation, such as maternal malnutrition, generally noticed to increase fetal deaths, particularly among males, unlike Anderson's study of 138 years' trends. Also, higher incidence of Hepatitis-B virus in populations is believed to have decreased the male to female sex ratio (Florida 2008). Contrary to this finding, Oster examined a data set of 67,000 births in China, where $15 \%$ of who were Hepatitis-B carriers and found no effect in either the mother's or father's hepatitis on sex ratio at birth (Bethmann and Kvasnicka 2013).

A further research by a group, led by Ein-Mor, suggested that sex ratio does not seem to change significantly with either maternal or paternal age, adding that the natural level of parity does not affect the male-to-female ratio, though there is a significant association of sex ratio with the length of gestational periods (Heer and Grossbard-Shechtman 1981). This conclusion has been disputed by James, suggesting that Ein-Mor's results are based on some demographic variables and a small data set, stating that in a broader study of variables and taking a larger population samples, the human sex ratio showed substantial variation for various reasons and different trend effects of length of gestation than those reported by Ein-Mor, concluding that human sex ratios and mammalian sex ratios in general, are causally related to the hormonal levels of both parents at the time of fertilization and conception.

The Arctic Monitoring and Assessment Program (2007) noted abnormally low sex ratios in Russian Arctic villages and Inuit villages in Greenland and Canada (Smith and Von Behren 2005). This monitoring group attributed this imbalance to high levels of endocrine disruptors in the blood of inhabitants, including PCB (Poly Chlorinated Biphenyl) and DDT (Dichloro Diphenyl Tricgloroethane) where the chemicals are believed to have accumulated in the tissues of fish, which are the main diets of the populations around.

In this connection, a research paper published in 1999 by scientists from Finland's National Public Health Institute reported the effects of environmental chemicals on changes in sex ratio over 250 years in Finland (Jacobsen et al. 1999). Accordingly, a scientific team evaluated whether Finnish long-term data are compatible with the hypothesis that the decrease in the ratio of male to female births in industrial countries is caused by environmental factors. Their analysis of births from the statistical documents of Finland and all live births in Finland from 1751 to 1997 indicated an increase in the proportion of males, followed by a decrease and interrupted by peaks in births of males during and after World War I and World War II.

In the same paper, it is indicated that latitude can have an impact on sex differentials where countries near the equator produce more females than those near 
the poles (Vartiainen, Kartovaara, and Tuomisto 1999). These scientists found that the peak ratio of male proportion precedes the period of industrialization or the introduction of pesticides or hormonal drugs, rendering a causal association between environmental chemicals and human sex ratio at birth. Moreover, these scientists claimed that the trends found in Finland are similar to those observed in other countries with worse pollution and much greater pesticide uses.

\section{ANALYSIS OF VARIATIONS AT THE LEVELS OF SEX RATIOS AMONG THE COUNTRIES}

\section{Measures of Dispersion and Standard Deviation}

In light of the documented available data of sex ratios, the variations in the ratios among the selected worldwide 35 major countries and continents (Appendix B) are examined by applying the mean and standard deviation statistical techniques. The computational steps are as follows:

(1) Let $X_{1}, X_{2}, X_{3}, \ldots X_{35}$ be the observed sex ratios, shortened as $X_{i}$, where

$\mathrm{i}=1,2,3, \ldots 35$; with " $\bar{X}$ " as the mean and "S" as standard deviation.

(2) The mean is computed: $\bar{X}=\frac{1}{n} \sum_{i=1}^{n} X_{\mathrm{i}}$; where $\mathrm{n}=35 ;$ standard deviation $\mathrm{S}=\sqrt{\frac{1}{n}} \sum_{i=1}^{n}\left(X_{i}-\bar{X}\right)^{2}$

(3) From data in Appendix B, $\bar{X}=\frac{3717}{35}=$ 106.2 and $\mathrm{S}=\sqrt{\frac{1}{n}} \sum_{i=1}^{n}\left(X_{i}-\bar{X}\right)^{2}=\sqrt{\frac{0}{35}}=0$

Hence, there has not been any significant difference in the sex ratio at live birth among the countries in Appendix B.

\section{Bivariate Frequency Distributions of the Sex Ratios}

Our interest in this section is focused on analysing the empirical data on the sex ratios at birth delivery. For this purpose, the frequency distributions of the ratios are organized in Appendix A for African countries and Appendix B for selected major worldwide regions/countries, respectively.

As shown in Appendix A1, sex ratio at birth stands at an average of about 103 males per 100 females for African regional organizations with the exception for North African region where the sex ratio is about 105 .

At country levels, the ratios are generally about 103 except for North African countries ranging between 104 and 107; Sudan in IGAD region (105); Chad and Rwanda in Central Africa (104 and 102, respectively); Mauritius (105), Mozambique (102), South Africa (102), and Zimbabwe (102). Interestingly, a large number of the ECOWAS countries recorded between 104 and 105 (refer to Appendix A3).

As could be noted in Appendixs A and B, the ratios at birth appear to be significantly higher in the advanced countries than those for African regional states and corresponding countries (refer to Appendixs A1-A3) and for Latin American, Asian, European, and other major countries (Appendix B). These variations could largely be explained by probably the prevalence/incidence of high wastages during fertilization and conception for African women as compared with those in the developed countries, Asian and Latin American countries where antenatal, pregnancy, and delivery health services used to be better than that in the African continent. Furthermore, as explained in Section II, these patterns could possibly be explained by the variations of the impact of the demographic, health, other socio-economic factors; gestational and environmental factors, natural factors, and differentials in population progrmmes 
among the developed and underdeveloped countries in the world.

\section{Analysis of Variance (ANOVA)}

In the light of the available base data of sex ratios, the application of ANOVA techniques to sex ratio differentials among the African regional organizations and countries is relevant whereas application of measures of central tendency technique is applicable to be used for the continents and countries outside Africa (Freund 2004). Accordingly, these techniques enable us to investigate the variations of human sex ratios at birth among the countries of the worldwide developed and developing societies.

The base line data are presented in Appendix A where Appendix A1 presents for the five African regional organizations/states and Appendixs A2 and A3 for the 50 African countries whereas Appendix B presents for the 35 major continents and countries outside Africa.

Analysis of variance. The variations of the African sex ratios are executed at the following two locational levels:

Level 1: Sex ratio variations among the five regional states of Africa;

Level 2: Variations among the 50 African countries, separately at live births.

(1) Formulation of hypothesis testing:

There are two hypotheses testing, namely, the null-hypothesis $\left(\mathrm{H}_{0}\right)$ and the alternative hypothesis $\left(\mathrm{H}_{1}\right)$. These two hypotheses are formally stated as follows:

$\mathrm{H}_{0}$ : There is no difference among the African regional states and countries and at world wide with respect to sex ratios of the four age categories;

$\mathrm{H}_{1}$ : otherwise.

One of the above two hypotheses has to hold true by comparing the parameters of statistical criteria, termed as " $F$ " values, where one is calculated by statistical procedures and the other one is obtained from standard statistical table. These values are conveniently represented by $\mathrm{F}(\mathrm{cal})$ and $\mathrm{F}(\mathrm{tab})$, read as F-calculated and F-tabulated, respectively.

(2) Decision criteria:

(a) If $\mathrm{F}(\mathrm{cal})>\mathrm{F}(\mathrm{tab})$, then $\mathrm{H}_{0}$ is rejected, otherwise accepted, i.e. $\mathrm{H}_{1}$ is accepted;

(b) If $\mathrm{F}(\mathrm{cal})<\mathrm{F}(\mathrm{tab})$, then $\mathrm{H}_{0}$ is accepted.

Level 1: Computed analysis of variance at African regional organizations:

As shown in Table 1 below, since the computed $\mathrm{F}$ is less than the tabulated $\mathrm{F}$ in standard table with $\mathrm{df}$ ( 4 , $15)$, the null-hypothesis $\left(\mathrm{H}_{0}\right)$ is accepted. This means that there does not appear any significant variations in the sex ratios among the five African regional organizations, with a value of .1103.

Examination of the sex ratio variations among the 50 African countries is also made and the results are presented in Appendixs A2 and A3. It indicates that the computed $\mathrm{F}$ value is higher than the standard tabulated $F$ value at $\mathrm{df}(4,45)$. Accordingly, as presented in Table 2, the null-hypothesis $\left(\mathrm{H}_{0}\right)$ is rejected with a value of 8.75 , implying that there appears some variations among the 50 African countries at 5\% significance level, though the reported data apparently show similar sex ratios at birth for a large number of African countries, standing at about 103 males per100 female live births.

\section{CONCLUSIONS}

The SRB among the countries varies with socio-economic status, gestational periods, environmental conditions, natural factors; patriarchal/traditional society; parent's health; maternal malnutrition; psychological stress; the hormonal complications during fertilization and conception, medical technology, and hormonal drugs. The ratios are consistently higher for the advanced countries than the developing countries, with highest for China and India.

Attempts are made to further examine the level of variations in the sex ratios among the countries applying the analysis of variance technique and 
Table 1. ANOVA Results for African Regional Organizations/States

\begin{tabular}{lllll}
\hline Sources of variation & Degree of freedom (df) & $\begin{array}{l}\text { Sum of squares } \\
\text { (SS) }\end{array}$ & $\begin{array}{l}\text { Mean of squares } \\
\text { (MS) }\end{array}$ & $\begin{array}{l}\text { F(cal) } \\
\text { value }\end{array}$ \\
\hline Between treatment & 4 & .0061 & .00153 & .1103 \\
Error & 15 & .2080 & .01387 & - \\
SST & 19 & .2141 & - & - \\
\hline
\end{tabular}

Note: SS = Sum of squares of all individual observations; MS = SS / DF; SST = SS - CF where CF = Correction Factor, F(tab) = 3.06 and $\mathrm{df}=(4,15)$ at $5 \%$ level of significance.

Table 2. Summary Results of ANOVA for the 50 African Countries

\begin{tabular}{lllll}
\hline Sources of variation & Degree of freedom $(\mathrm{df})$ & $\begin{array}{l}\text { Sum of squares } \\
(\mathrm{SS})\end{array}$ & $\begin{array}{l}\text { Mean of squares } \\
(\mathrm{MS})\end{array}$ & $\begin{array}{l}\mathrm{F}(\mathrm{cal}) \\
\text { value }\end{array}$ \\
\hline Between treatment & 4 & .0028 & .00070 & 8.7500 \\
Error & 45 & .0034 & .00008 & \\
SST & 49 & .0062 & & \\
\hline
\end{tabular}

Note: SS = Sum of squares of all individual observations; MS = SS / DF; SST = SS - CF where CF $=$ Correction Factor; F(cal) = $8.75, \mathrm{~F}(\mathrm{tab})=2.58$ and $\mathrm{df}=(4,45)$ at $5 \%$ level of significance.

measures of central tendency and the outputs manifest the following features:

(1) It is found that there is no significant differences among the five African regional organizations with respect to their overall levels and patterns of the sex ratios at birth; but some variations are indicated among the 50 African countries;

(2) Applying the measures of dispersion statistical model on the sex ratio distributions among the selected European, Asian, and Latin American countries, the standard deviation is computed to be about zero, implying that the levels of their sex ratios are similar, with a mean of about 1.06 .

\section{Recommendation}

It is suggested that a research on the levels and patterns of sex ratios at chromosomal stages of human fertilization and conception can be undertaken in order to understand any occurrence of wastages of conception and overall antenatal processes in order to establish linkages with the outcomes of the sex ratios at live birth delivery.

\section{Study Limitation}

Ideally, the sources of data of the study should have been based on the modern outputs of continuous vital statistics registration system of births, deaths, and marriages of each country. However, worldwide comprehensive modern civil registration system practice has been incomplete, particularly non-existent in the African continent. Alternatively, the study is based on secondary data mostly compiled by the main international bodies from the results of various DHS, WFS, civil registration system for some European countries such as Scandinavian countries and the results of National Population and Housing Censuses of various countries in the world. Accordingly, the authors could not apply appropriate statistical models, such as multivariate regression and logistic models, for the authors found out that the available data at macro-level were limited to apply descriptive frequency distribution tables, estimation of central tendencies (i.e. mean and standard deviations), and ANOVA. 


\section{APPENDIX}

\section{Appendix A: Levels of Sex Ratios at Birth of African Populations}

Appendix A1: Comparison of Sex Ratios at Birth of the African Regional States

\begin{tabular}{llll}
\hline SR. No. & African regional states & $\begin{array}{l}\text { Total } \\
\text { countries }\end{array}$ & $\begin{array}{l}\text { Sex ratios } \\
\text { at birth }\end{array}$ \\
\hline 1 & North A. & 6 & 1.05 \\
2 & IGAD & 7 & 1.03 \\
3 & SADC & 13 & 1.03 \\
4 & ECOWAS & 16 & 1.03 \\
5 & ECCAS & 8 & 1.03 \\
All & Africa & 50 & 1.03 \\
\hline
\end{tabular}

Note: Source: Summary of Appendix A2 and A3.

Appendix A2: Sex Ratio Variations Among North, IGAD, and ECCAS Regional Countries

\begin{tabular}{lllllll}
\hline SR. No. & $\begin{array}{l}\text { Northern African } \\
\text { countries }\end{array}$ & Sex ratios & IGAD countries & Sex ratios & ECCAS countries & Sex ratios \\
\hline 1 & Algeria & 1.05 & Djibouti & 1.04 & Burundi & 1.03 \\
2 & Egypt & 1.05 & Eritrea & 1.03 & Chad & 1.04 \\
3 & Libya & 1.05 & Ethiopia & 1.03 & Cameron & 1.03 \\
4 & Morocco & 1.06 & Kenya & 1.03 & Central A. Rep & 1.03 \\
5 & Tunisia & 1.07 & Somalia & 1.03 & Congo (Zaire) & 1.03 \\
6 & W. Sahara & 1.04 & Sudan (2) & 1.05 & Congo (Kinsasa) & 1.03 \\
7 & Mean (6) & 1.05 & Uganda & 1.03 & Equatorial G. & 1.03 \\
8 & & & Mean (7) & 1.03 & Rwanda & 1.02 \\
9 & & & & Mean (8) & 1.03 \\
\hline
\end{tabular}

Appendix A3: Sex Ratios Variations Among SADC and ECOWAS Regional Countries

\begin{tabular}{lllll}
\hline SR. No. & SADC countries & Sex ratios & ECOWAS countries & Sex ratios \\
\hline 1 & Botswana & 1.03 & Benin & 1.05 \\
2 & Comoros & 1.03 & Burkina F. & 1.03 \\
3 & Lesotho & 1.03 & Cape V. & 1.03 \\
4 & Madagascar & 1.03 & Ivory C. & 1.03 \\
5 & Malawi & 1.03 & Gabon & 1.03 \\
6 & Mauritius & 1.05 & Gambia & 1.03 \\
7 & Mozambique & 1.02 & Ghana & 1.04 \\
8 & Namibia & 1.03 & Guinea & 1.03 \\
9 & Seychelles & 1.03 & Liberia & 1.04 \\
10 & South Africa & 1.02 & Mali & 1.05 \\
11 & Tanzania & 1.03 & Mauritania & 1.05 \\
12 & Zambia & 1.03 & Niger & 1.05 \\
13 & Zimbabwe & Nigeria & 1.06 \\
14 & Mean (13) & 1.02 & Senegal & 1.03 \\
15 & & 1.03 & Sierra L & 1.03 \\
16 & & Togo & 1.03 \\
17 & & Mean (16) & 1.04 \\
\hline
\end{tabular}

Notes: Source: Compiled and rearranged for African countries from following Sources:

(1) Gender Statistics Highlights: World Data Bank by the World Bank, February 2012;

(2) International Data Base: World Data Bank (WHS) and US Bureau of the Census (2007-2011);

(3) Michel Garenne: Directeur de Recherche, IRD/ISD, 15 rue de l'école de medicine, 5270 Paris, Cedex 06;

(4) The Free Encyclopedia (Wikipedia): A Review of Sex Ratios, Africa Populations. 


\section{Appendix B: Sex Ratio Variations Among Some European, Asian, and Latin American Countries}

\begin{tabular}{llllll}
\hline SR. No. & $\begin{array}{l}\text { Country/ } \\
\text { continent }\end{array}$ & $\begin{array}{l}\text { Sex } \\
\text { ratios }\end{array}$ & SR. No. & $\begin{array}{l}\text { Country/ } \\
\text { continent }\end{array}$ & $\begin{array}{l}\text { Sex } \\
\text { ratios }\end{array}$ \\
\hline 1 & Argentina & 1.05 & 11 & Japan & 1.06 \\
2 & Australia & 1.06 & 12 & Malaysia & 1.07 \\
3 & Bangladesh & 1.04 & 13 & Mexico & 1.05 \\
4 & Brazil & 1.05 & 14 & Norway & 1.05 \\
5 & Canada & 1.6 & 15 & Pakistan & 1.10 \\
6 & China & 1.13 & 16 & Russia & 1.05 \\
7 & Euro-Union (15) & 1.06 & 17 & Sweden & 1.06 \\
8 & India & 1.12 & 18 & UK & 1.05 \\
9 & Indonesia & 1.05 & 19 & USA & 1.05 \\
10 & Israel & 1.05 & 20 & Total (33) & 1.06 \\
\hline
\end{tabular}

Notes: Source: Compiled and arranged from:

(1) World Data Bank (WHS), World Bank, February 2012;

(2) Michel Garenne, Directeur de Recherche, IRD/ISD, 15 rue de l'école de médecine, 75270 Paris, Cedex 06 (World Maps);

(3) International Data Base, US Bureau of the Census (2007-2011).

\section{Notes}

1. UN. 1983. Manual X: Indirect Techniques for Demographic Estimation. Population Studies, no. 81, UN, New York. Pp. 34-37 and 74-81.

2. Coale, A. J. and P. Demeny. 1966. Regional Model Life Tables and Stable Populations. Princeton, New Jersey: Princeton University Press.

\section{References}

Anderson, B. A. and B. D. Silver. 1986. "Infant Mortality in the Soviet Union: Regional Differences and Measurement Issues." Population and Development Review 12(4):705-738.

Anderson, R. and S. Bergstrom. 1998. "Is Maternal Malnutrition Associated With a Low Sex Ratio at Birth?" Human Biology 70(6):1101-1106.

Bernstein, M. E. 1958. "Studies in the Human Sex Ratio. 5. A Genetic Explanation of the Wartime Increase in the Secondary Sex Ratio." American Journal of Human Genetics 10(1):68-70.

Bethmann, D. and M. Kvasnicka. 2013. "World War II, Missing Men and out of Wedlock Childbearing." Economic Journal 123(567):162-194.

Branum, A. M., J. D. Parker, and K. C. Schoendorf. 2009. "Trends in US Sex Ratio by Plurality, Gestational Age and Race/Ethnicity." Human Reproduction 24(11):2936-2944.

Cai, Y. and W. Lavely. 2003. "China's Missing Girls: Numerical Estimates and Effects on Population Growth." The China Review 3(2):13-29.
Catalano, R. A. 2003. "Sex Ratios in the Two Germanies: A Test of the Economic Stress Hypothesis." Human Reproduction 18(9):1972-1975.

Catalano, R., T. Bruckner, and K. R. Smith. 2008. "Ambient Temperature Predicts Sex Ratios and Male Longevity." Proceedings of the National Academy of Sciences 105(6):2244-2247.

David, D. L., M. B. Gottlieb, and J. R. Stampnitzky. 1998. "Reduced Ratio of Male to Female Births in Several Industrial Countries: A Sentinel Health Indicator?" JAMA 279(13):1018-1023.

Ein-Mor, E., D. Mankuta, D. Hochner-Celnikier, A. Hurwitz, and R. Haimov-Kochman. 2010. "Sex Ratio Is Remarkably Constant." Fertility and Sterility 93(6):1961-1965.

Florida, R. 2008. A Singles Map of the United States of America. The Boston Globe. Retrieved (http://archive. boston.com/bostonglobe/ideas/articles/2008/03/30/a_single s_map_of_the_united_states_of_america/?s_campaign=8315).

Freund, J. E. 2004. Modern Elementary Statistics, Chapter 4: Summarizing Data: Measures of Variation, pp. 76-85; and Chapter 15: Analysis of Variance, pp. 363-389.

Garenne, M. 2002. "Sex Ratios at Birth in African Populations: A Review of Survey Data." Human Biology 74(6):889-900.

Government of India. 2011. "Size, Growth Rate and Distribution of Child Population." Office of Census Commissioner, Ministry of Home Affairs, India.

Grossbard, S. A. and A.-D. Catalano. 2005. Marriage Markets and Married Women's Labor Force Participation. Retrieved (http://citeseerx.ist.psu.edu/viewdoc/download? doi=10.1.1.572.5828\&rep=rep1\&type=pdf).

Heer, D. M. and A. Grossbard-Shechtman. 1981. "The Impact of the Female Marriage Squeeze and the Contraceptive 
Revolution on Sex Roles and the Women's Liberation Movement in the United States, 1960 to 1975." Journal of Marriage and the Family 43(1):49-65.

Hudson, V. M. and A. M. den Boer. 2004. Bare Branches: The Security Implications of Asia's Surplus Male Population. Cambridge, MA: MIT Press.

Jacobsen, R., H. Møller, and A. Mouritsen. 1999. "Natural Variation in the Human Sex Ratio." Human Reproduction 14(12):3120-3125.

James, W. H. 1987. "The Human Sex Ratio. Part 2: A Hypothesis and a Program of Research." Human Biology 59(6): 873-900.

—. 2008. "Evidence That Mammalian Sex Ratios at Birth Are Partially Controlled by Parental Hormonal Levels Around the Time of Conception." Journal of Endocrinology 198(1):3-15.

—. 2010. "Inconstancy of Human Sex Ratios at Birth." Fertility and Sterility 94(3):e53.

—. 2011. "The Human Sex Ratio. Part 1: A Review of the Literature." Human Biology 59(5):721-752.

Kristof, N. and S. WuDunn. 2009. Half the Sky: Turning Oppression Into Opportunity for Women Worldwide. Pulitzer Center on Crisis Reporting.

Mathews, T. J. and B. E. Hamilton. 2005. "Trend Analysis of the Sex Ratio at Birth in the United States." Natl Vital Stat Rep 53(20):1-17.

Merli, M. G. and A. E. Raftery. 2000. "Are Births Underreported in Rural China? Manipulation of Statistical Records in Response to China's Population Policies." Demography 37(1):109-126.

Mesle, F., J. Vallin, and I. Badurashvili. 2007. "A Sharp Increase in Sex Ratio at Birth in the Caucasus. Why? How?' In Watering the Neighbour's Garden: The Growing Demographic Female Deficit in Asia, edited by I. Attane and C. Z. Guilmoto. Paris, France: Committee for International Cooperation in National Research in Demography (CICRED).

Oster, E., G. Chen, X. S. Yu, and W. Y. Lin. 2008. "Hepatitis B Does not Explain Male-Biased Sex Ratios in China." NBER Working Paper No. 13971.

Pongou, R. 2013. "Why Is Infant Mortality Higher in Boys Than in Girls? A New Hypothesis Based on Preconception Environment and Evidence From a Large Sample of Twins." Demography 50(2):421-444.
Ruder, A. 1985. "Paternal-Age and Birth-Order Effect on the Human Secondary Sex Ratio." American Journal of Human Genetics 37(2):362-372.

Smith, D. and J. Von Behren. 2005. "Trends in the Sex Ratio of California Births, 1960-1996." J Epidemiol Community Health 59(12):1047-1053.

The Guardian. 2007. Man-Made Chemicals Blamed as Many More Girls Than Boys Are Born in Arctic. Retrieved (https://www.theguardian.com/world/2007/sep/12/gender.sc iencenews).

U.S. Department of Health and Human Services. 2011. "Trend Analysis of the Sex Ratio at Birth in the United States." National Center for Health Statistics.

USA/CIA. 2006. World Factbook.

Vartiainen, T., L. Kartovaara, and J. Tuomisto. 1999. "Environmental Chemicals and Changes in Sex Ratio: Analysis Over 250 Years in Finland." Environmental Health Perspectives 107(10):813-815.

Zhang, G. Y. 2004. "Very Low Fertility in China in the 1990s: Reality or an Illusion Arising From Birth Underreporting?" Presented at the Annual Meeting of the Population Association of America, April 1-3, Boston.

\section{Bios}

Hadgu Bariagaber, Ph.D., senior lecturer (expert in quantitative and qualitative data collection and analysis) in the Department of Population Studies, Faculty of Social Sciences, University of Botswana, Botswana; research fields: population and sustainable development, being engaged in wide range research activities dealing with population theories, demographic and epidemiological transition, HIV/AIDS, socio-economic correlates of fertility and mortality, historical perspectives of the reciprocal relationship between population and development, advanced demographic and mathematical models in demographic research analysis applying statistical models such as linear and multiple regression, multivariate data analysis.

Mpho Keetile, Ph.D. candidate, lecturer, Department of Population Studies, Faculty of Social Sciences, University of Botswana, Botswana; research fields: population and gender, health, morbidity and mortality, sexual reproductive health and rights. 